10

\title{
Спектральная сенсибилизация фото-ЭдС в монокристаллическом кремнии
}

\author{
(C) М.А. Горяев \\ Российский государственный педагогический университет им. А.И. Герцена, \\ 191186 Санкт-Петербург, Россия \\ e-mail: mgoryaev@mail.ru
}

Поступила в редакцию 11.05.2018 г.

В окончательной редакции 11.05.2018 г.

Принята к публикации 22.02.2019 г.

Исследовано влияние нанесенного на поверхность полупроводника органического красителя на спектр фото-ЭДС в монокристаллическом кремнии. Обнаружена сенсибилизация внутреннего фотоэффекта в полупроводнике в полосе поглощения красителя. Определена оптимальная концентрация красителя на поверхности полупроводника, которая соответствует толщине пленки красителя 10-15nm. Обсужден механизм сенсибилизации на основе теории безызлучательного индуктивно-резонансного переноса энергии от красителя полупроводнику.

Ключевые слова: монокристаллический кремний, фотовольтаический эффект, сенсибилизация красителями.

DOI: $10.21883 /$ OS.2019.07.47945.133-19

Органические красители эффективно сенсибилизируют фотоэлектрические и фотохимические процессы в видимой и ближней инфракрасной области спектра в широкозонных $\left(E_{g}>2.5 \mathrm{eV}\right)$ полупроводниках (AgHal, $\mathrm{ZnO}, \mathrm{TiO}_{2}$ и других) [1-4]. В галоидосеребряной фотографии сенсибилизация красителями является наиболее эффективным способом управления уровнем и спектром чувствительности классических фотографических материалов [1]. Фотоэлектрохимические ячейки на основе частиц двуокиси титана с сенсибилизирующими красителями предлагаются как альтернативные кремниевым солнечным батареям [5].

Основным недостатком солнечных элементов на базе кристаллического кремния является относительно невысокий коэффициент экстинкции в области непрямых переходов, поэтому толщина изготавливаемых на основе этого полупроводника фотоэлектрических преобразователей должна составлять сотни микрон [68]. Кремниевые ПЗС-матрицы используются в качестве приемников изображения в современных системах электронной фотографии [9], а применение светофильтров в системе цветоделения приводит к потере энергии и полезной информации [10]. В работе [11] была показана возможность спектральной сенсибилизации красителями СВЧ фотопроводимости узкозонных полупроводников, а в [12] обнаружена эффективная сенсибилизация красителями фотопроводимости порошкообразного кремния на постоянном токе.

В настоящей работе исследован фотовольтаический эффект в монокристаллическом кремнии и влияние на его эффективность нанесенных на поверхность полупроводника органических красителей.
Для исследования использовались плоские монокристаллы площадью $1-2 \mathrm{~cm}^{2}$ толщиной $0.5 \mathrm{~mm}$. На поверхность полупроводника наносились красители из этанольного раствора определенной концентрации путем естественного испарения растворителя при комнатной температуре. Измерения фото-ЭДС монокристаллических образцов проводилось конденсаторным методом [13] при модулированном освещении. Для оценки эффективности внутреннего фотоэффекта измеряемые сигналы $\Delta U$ нормировались на одинаковое количество падающих на образец квантов света.

На рисунке представлены дифференциальные спектры конденсаторной фото-ЭДС кремния при различных концентрациях нанесенного на поверхность полупроводника красителя относительно исходного образца.

Приведенные результаты показывают, что фото-ЭДС окрашенных образцов в области поглощения красителей отличается от сигнала для неокрашенного кремния. Величина наблюдаемого эффекта сенсибилизации зависит от количества нанесенного на поверхность полупроводника красителя: при увеличении концентрации красителя фото-ЭДС сначала растет (кривые 1 и 2), а затем происходит уменьшение сигнала (кривые 3 и 4). Максимальное увеличение фото-ЭДС в монокристаллическом кремнии достигает нескольких процентов [14], что существенно меньше сенсибилизированного фотоэффекта в порошкообразных образцах, где фотопроводимость полупроводника с нанесенными красителями более чем на порядок превосходит фотопроводимость неокрашенного кремния [12]. Это связано прежде всего с тем, что удельная поверхность мелкодисперсных порошков на несколько порядков больше, чем у монокристалла. 


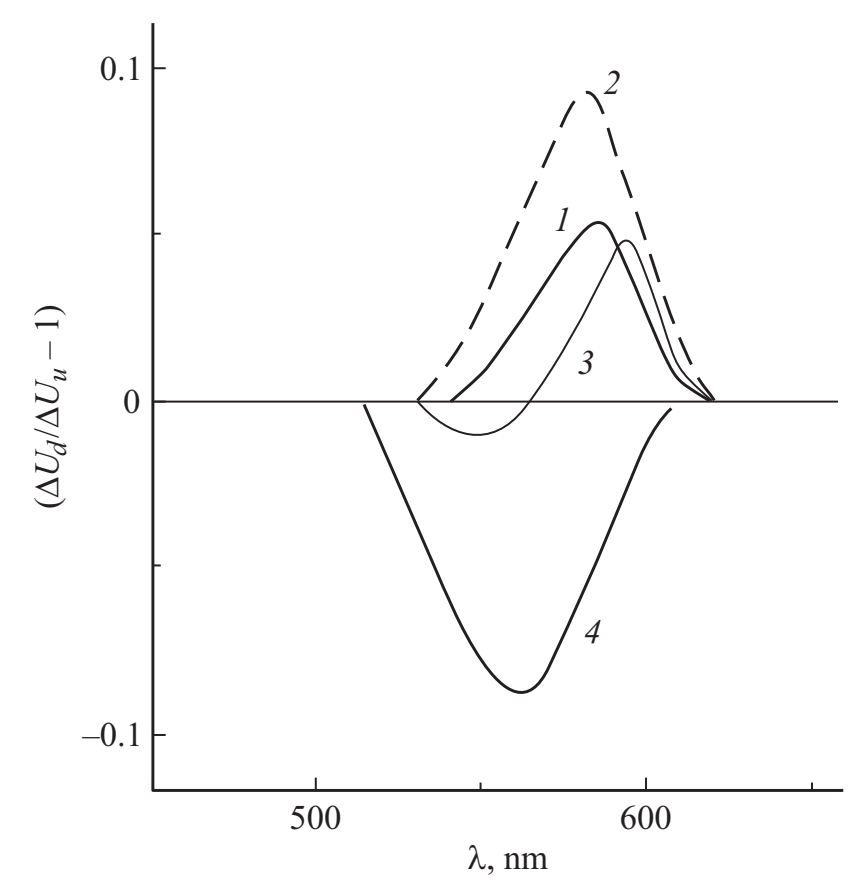

Дифференциальные спектры фото-ЭДС $\Delta U_{d}$ окрашенных родамином 6Ж образцов относительно фото-ЭДС $\Delta U_{u}$ неокрашенного кремния. Поверхностные концентрации молекул красителя $15(1), 30(2), 60(3)$ и $100 \mathrm{~nm}^{-2}(4)$.

Уменьшение фото-ЭДС при увеличении количества нанесенного красителя (рисунок, кривые 3 и 4 ) связано с увеличением толщины пленки красителя на поверхности полупроводника. При увеличении толщины пленки возрастает поглощение красителя и возрастает роль внутримолекулярной конверсии энергии фотовозбуждения по колебательным и вращательным степеням свободы, и часть падающей на образец энергии не доходит до кристалла. В итоге проявляется фильтровой эффект в полосе поглощения нанесенного на поверхность полупроводника красителя, как это наблюдается при сенсибилизации гидрида алюминия красителями [15-17].

Рассмотрим происходящие в системе краситель-полупроводник процессы при поглощении света красителем. При фотовозбуждении красителя в молекуле могут осуществляться как безызлучательные, так и излучательные электронные переходы. Скорость внутренней деградации энергии зависит от жесткости скелета молекулы красителя, обусловливающей возможность размена энергии электронного возбуждения по колебательным и вращательным степеням свободы. Для большинства красителей на поверхности твердых тел наблюдается ужесточение структуры молекулы, и вероятность внутримолекулярной конверсии становится несущественной. В связи с этим на диэлектриках квантовый выход люминесценции адсорбированных красителей составляет десятки процентов, а на металлах, узкозонных полупроводниках и хорошо сенсибилизируемых фоточувствительных широкозонных полупроводниках (например, галогенидах серебра и окиси цинка) свечение отсутствует вследствие эффективной передачи энергии фотовозбуждения адсорбенту $[3,4,18]$.

Одна из основных причин тушения люминесценции в таких системах - наличие в запрещенной зоне полупроводника локальных электронных состояний, способных акцептировать энергию от красителя [3,4]. В кремнии плотность таких состояний более чем достаточна для полного тушения люминесценции, поскольку данный интервал энергий соответствует переходам электронов из валентной в зону проводимости. А значительное увеличение эффективности генерации свободных носителей при передаче энергии от красителя по сравнению с поглощением в собственной области полупроводником может быть обусловлено тем, что это поглощение формируется непрямыми электронными переходами.

Следует отметить, что увеличение фотовольтаического эффекта при поглощении света красителем происходит также из-за того, что вследствие небольшого коэффициента экстинкции кремния собственное поглощение света и генерация носителей происходит на относительно большой глубине кристалла. А эффективный радиус переноса энергии при сенсибилизации красителями составляет несколько нанометров [2], поэтому возрастает роль приповерхностной генерации фотоэлектронов.

Оптимальная для сенсибилизации концентрация красителя на поверхности монокристалла составляет величину $30 \mathrm{~nm}^{-2}$ (рисунок). С учетом того, что площадь молекул красителя составляет величину $0.7-1.4 \mathrm{~nm}^{2}$ [1], это соответствует оптимальной толщине пленки красителя около 30 монослоев или $10-15 \mathrm{~nm}$. Поскольку эффективный радиус переноса энергии при сенсибилизации красителями составляет 5-7 nm [2], то часть поглощенной красителем энергии не доходит до полупроводника. Кроме того, при увеличении толщины пленки и поглощения света красителем возрастает роль внутримолекулярной конверсии энергии по колебательным и вращательным степеням свободы. Все это в итоге приводит к проявлению фильтрового эффекта в полосе поглощения нанесенного на поверхность кристалла красителя.

Спектры сенсибилизированного фотоэффекта смещены относительно спектров фильтрового эффекта (рисунок, кривые 3 и 4). Это обусловлено тем, что в соответствии с теорией индуктивно-резонансного безызлучательного переноса энергии эффективность этого процесса $\mathrm{K}$ зависит от интеграла перекрытия спектра люминесценции донора и спектра поглощения акцептора энергии $[19,20]$ :

$$
K=C \int I_{d}(v) \varepsilon_{a}(v) v^{-4} d v
$$

где $I_{d}-$ квантовая спектральная плотность излучения люминесценции донора, $\varepsilon_{a}(v)-$ молярный десятичный коэффициент поглощения акцептора, $v-$ волновое число, $C$ - постоянная. Интеграл перекрытия сильно 
зависит от волнового числа, что подтверждается более заметным тушением люминесценции красителей в длинноволновой области спектра при передаче энергии твердому телу [21]. В связи с этим эффективность сенсибилизации в длинноволновой области должна быть больше, и спектр сенсибилизированного фотоэффекта смещен в область больших длин волн относительно спектра поглощения красителя, который определяет фильтровой эффект.

Обнаруженная сенсибилизация красителями фотоЭДС в кремнии может быть использована в таких полупроводниковых устройствах преобразования световой энергии в электрическую, как солнечные батареи или приемники изображения в современных системах электронной фотографии. В случае кремниевых солнечных батарей увеличение приповерхностной генерации свободных носителей может увеличить эффективность преобразования энергии и уменьшить толщину ячеек. Использование сенсибилизации красителями в ПЗСматрицах позволит улучшить систему цветоделения при регистрации цветных изображений подобно традиционной галоидосеребряной фотографии.

\section{Финансирование работы}

Работа выполнялась в рамках программы поисковых исследований, запланированных в РГПУ им. А.И. Герцена.

\section{Благодарности}

Автор благодарен С.В. Федичкину за помощь в создании экспериментальной установки.

\section{Конфликт интересов}

Автор заявляет, что у него нет конфликта интересов.

\section{Список литературы}

[1] Джеейм T.X. Теория фотографического процесса. Л.: Химия, 1980. 672 c.; James T.H. The Theory of the Photographic Process. New York: Macmillan Publ. Company, 1977.

[2] Акимов И.А., Черкасов Ю.А., Черкашин М.И. Сенсибилизированный фотоэффект. М.: Наука, 1980. 384 с.

[3] Акимов И.А., Горяев М.А. // Журн. физ. химии. 1984. Т. 58. № 5. C. 1104.

[4] Горяев М. Физические основы фотохимии твердого тела. Фотолиз неорганических твердых тел. Deutschland, Saarbrucken: Lambert Acad. Publ., 2013. 134 c.

[5] Gratzel M. // J. Photochem. Photobiol. C: Photochem. Rev. 2003. V. 4. N 2. P. 145.

[6] Алферов Ж.И., Андреев В.М., Румянцев В.Д. // ФТП. 2004. T. 38. № 8. C. 937; Alferov Zh.I., Andreev V.M., Rumyantsev V.D. // Semiconductors. 2004. V. 38. N 8. P. 899.

[7] Абанасьев В.П., Теруков Е.И., Шерченков А.А. Тонкопленочные солнечные элементы на основе кремния. СПб.: Изд. СПбГЭТУ „ЛЭТИ“, 2011. 168 с.
[8] Duffie J.A., Beckman W.A. Solar Engineering of Thermal Processes. N.Y.: John Wiley \& Sons Inc., 2013.

[9] Boyle W.S. // Rev. Modern Physics. 2010. V. 82. Fasc. 3. P. 2305.

[10] Горяев М.А., Дудников Ю.А. // Ж. научн. и прикл. фотогр. и кинематогр. 1990. Т. 35. № 5. С. 386.

[11] Ионов Л.Н., Акимов И.А. // Письма в ЖТФ. 1975. Т. 1. № 3. C. 881; Ionov L.N., Akimov I.A. // Sov. Techn. Phys. Lett. 1975. V. 1. N 3. P. 384.

[12] Горяев М.А. // Журн. физ. химии. 2015. Т. 89. № 12. C. 1940; Goryaev M.A. // Rus. J. Phys. Chem. A. 2015. V. 89. N 12. P. 2320.

[13] Акимов И.А. // Опт.-мех. пром. 1966. № 5. С. 4; Akimov I.A. // Sov. J. Opt. Technology. 1966. V. 33. N 5. P. 248.

[14] Goryaev M.A., Castro R.A. // Proc. 6th Intern. Conf. on Photonics, Optics and Laser Technology (PHOTOPTICS 2018). 2018. P. 130. doi 10.5220/0006525701300135

[15] Горяев М.А. // Опт. и спектр. 1980. Т. 49. № 6. С. 1142; Goryaev M.A. // Opt. Spectrosc. 1980. V. 49. N 6. P. 625.

[16] Горяев М.A. // Ж. научн. и прикл. фотогр. и кинематогр. 1981. T. 26. № 4. C. 283.

[17] Горяев М.А. // Опт. и спектр. 2000. Т. 88. № 1. С. 49; Goryaev M.A. // Opt. Spectrosc. 2000. V. 88. N 1. P. 42.

[18] Горяев М.А. // Письма в ЖТФ. 1980. Т. 6. № 11. С. 1132; Goryaev M.A. // Sov. Techn. Phys. Lett. 1980. V. 6. N 9. P. 484.

[19] Ермолаев В.Л., Свешникова Е.Б., Бодунов Е.Н. // Успехи физ. наук. 1996. Т. 166. № 3. С. 279; Ermolaev V.L., Sveshnikova E.B., Bodunov E.N. // Physics-Uspehi. 1996. V. 39. N 3. P. 261. doi 10.1070/PU1996v039n03ABEH000137

[20] Ermolaev V.L., Sveshnikova E.B., Bodunov E.N. // PhysicsUspehi. 1997. V. 40. N 3. P. 335. doi 10.1070/PU1997v040n03ABEH001592

[21] Горяев М.А., Акимов И.А. // Опт. и спектр. 1979. Т. 47. № 2. C. 409; Goryaev M.A., Akimov I.A. // Opt. Spectrosc. 1979. V. 47. N 2. P. 409. 